\title{
EXPERIMENTAL INVESTIGATION OF INFLUENCE WEDM PARAMETERS ON SURFACE ROUGHNESS AND FLATNESS DEVIATION
}

\author{
Dorota ONISZCZUK-ŚWIERCZ ${ }^{1}$, Rafał ŚWIERCZ1', Tomasz CHMIELEWSKI'1, \\ Tadeusz SAŁACIŃSKI ${ }^{1}$ \\ ${ }^{1}$ Warsaw University of Technology, Faculty of Production Engineering, EU, doo@meil.pw.edu.pl
}

https://doi.org/10.37904/metal.2020.3567

\begin{abstract}
Wire electrical discharge machining (EDM) is a modern technology that is widely used in the production of difficult to cut conductive materials. Stochastic nature of electrical discharges causing to difficult to identify the influence WEDM parameters on surface roughness and dimensional accuracy of machining parts. Predicting favorable machining conditions for the required surface finish and dimensional accuracy plays a key role in the process. Response surface methodology (RSM) was used to build empirical models on the influence of the discharge voltage $V B$, pulse interval $S B$, and workpiece height on the surface roughness $(R a)$ and the flatness deviation during the machining of tool steel X153CrMoV12. The conducted analysis of the material removal physics in relation to investigated parameters indicated potential sources of shape errors of cutting parts.
\end{abstract}

Keywords: WEDM, wire electrical discharge machining, flatness deviation, RSM, surface roughness

\section{INTRODUCTION}

Wire electrical discharge machining (WEDM) is wieldy using in manufacturing complex shape geometries with conductive materials. An advantage of WEDM technology is that it is possible to machine difficult to cat materials. The WEDM is included in a group of non-conventional technology with electrochemical machining [1-2], electrical discharge machining [3-5], and hybrid machining [6-8]. WEDM material is removed by a series of discharges occurring in the gap between the wire electrode and the workpiece. Electrical discharges cause melting and evaporation in local surface layers of both the workpiece and the working electrode [9-12]. The heat also causes evaporation of the dielectric liquid (deionized water) and induces high-pressure waves that wash the molten and/or vaporized metal. Shape accuracy is one of the most important functional features characterizing the wire electrical discharge machining. Predicting favorable machining conditions for the required surface finish and workpiece dimensional accuracy plays a very important role in planning the machining.

\section{MATERIALS AND METHODS}

The present paper was focused on the analyses of influence WEDM parameters and conditions on the surface roughness and flatness deviation of cut parts. Experimental studies were conducted on wire electrical discharge machine Mitsubishi MV 2400S. The electrode used was a brass wire with a dimension of $0.25 \mathrm{~mm}$ and deionized water was used as the dielectric. The cutting samples of tool steel X153CrMoV12 have dimensions of $200 \times 10 \times 10 \mathrm{~mm}, 250 \times 10 \times 10 \mathrm{~mm}$ and $300 \times 10 \times 10 \mathrm{~mm}$. The study was conducted according to experimental design, three levels, and three parameters. Experiments were conducted with the following machining conditions: discharge voltage in the range $V g=42-48 \mathrm{~V}$, pulse interval in the range $S B=9-11 \mu \mathrm{s}$, workpiece height $200-300 \mathrm{~mm}$. The measuring of surface flatness deviation of the cut slot was carried out on a Zeiss-Vista CNC coordinate measuring machine. In Calypso software, measuring paths have been 
determined (raster 300 points). The surface roughness of the slot after WEDM was measured using a FORM TALYSURF Series 2 scanning profilometer from Taylor Hobson GB. Figure 1 presents the experiment set up.

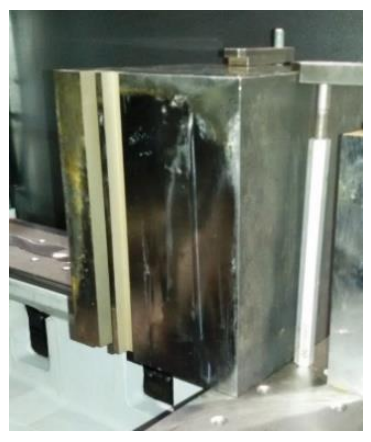

(a)
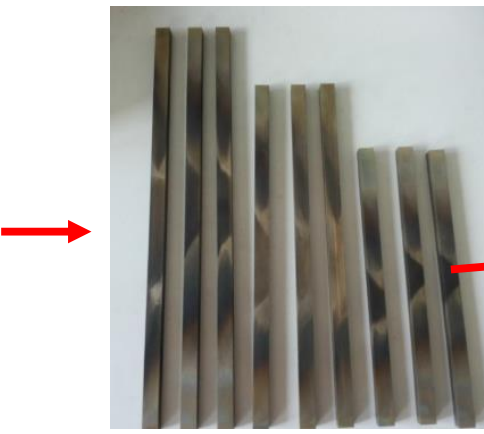

(b)

(c)

Figure 1 The experiment set up:(a) mounted block of material, (b) cut samples, (c) graphical presentation of measured flatness deviation on CMM

\section{RESULTS AND DISCUSSION}

Experimental investigation of the influence of the WEDM process parameters on the surface flatness deviation and roughness was carried out using response surface methodology (RSM). Table 1 shows the levels of machining parameters carried out in the experimental design.

Table 1 Design of the experimental matrix

\begin{tabular}{|c|c|c|c|c|c|}
\hline \multirow{2}{*}{ No. } & \multicolumn{3}{|c|}{ WEDM paramters } & \multicolumn{2}{c|}{ Observed values } \\
\cline { 2 - 6 } & $\boldsymbol{V G}$ & $\boldsymbol{S B}$ & $\boldsymbol{H}(\boldsymbol{m m})$ & $\boldsymbol{R} \boldsymbol{( \boldsymbol { \mu m } )}$ & $\boldsymbol{W}(\mathbf{m m})$ \\
\hline 1. & 42 & 9 & 200 & 2.08 & 0.023 \\
\hline 2. & 45 & 11 & 200 & 2.18 & 0.008 \\
\hline 3. & 48 & 10 & 200 & 2.20 & 0.013 \\
\hline 4. & 42 & 11 & 250 & 2.60 & 0.011 \\
\hline 5. & 45 & 10 & 250 & 2.32 & 0.011 \\
\hline 6. & 48 & 9 & 250 & 2.20 & 0.014 \\
\hline 7. & 42 & 10 & 300 & 2.68 & 0.019 \\
\hline 8. & 45 & 9 & 300 & 2.54 & 0.018 \\
\hline 9. & 48 & 11 & 300 & 2.66 & 0.016 \\
\hline
\end{tabular}

Results from the experimental studies were used to build an empirical model of influence discharge voltage $V g$, pulse interval $S B$, and workpiece height $H$ on the surface roughness and flatness deviation. To build an empirical model RSM was used. The regression equation was described by the polynomial function of the second degree:

$Y=\beta_{0}+\sum_{i=1}^{k} \beta_{i} X_{i}+\sum_{i=1}^{k} \beta_{i} i X_{i}^{2}+\sum_{i=1, i \neq j}^{k} \beta_{i j} i X_{i} X_{j}+\varepsilon$

The degree of fit of the regression equation to the results of the experimental studies described the ratio correlation $R$. The ratio $R$ was in the range $R \in<0,1>$. For the value of the coefficient $R$ approached unity, a more accurate fit of the regression equation to the research results will be obtained. The adequacy of the 
regression equation was checked with the Fishera-Snedecora test $(F)$. The value of the function test $F$ was calculated and compared with the critical value of the tables Fkr (read for the number of freedom at an established level of significance $\mathrm{p}$ ). The correlation coefficient $R$ was significant when there was a relation for the associated $p$-value $(p=0.05)$. After eliminating the non-significant terms, the final response equations for the surface roughness $R a$ and flatness deviation $W$ presented in equations 2-3. Table 2 presents the regression summaries for the established equations:

$$
\begin{aligned}
& R a=2.0164+0.000497 \cdot S B \cdot H-0.0166 \cdot V g \\
& W=0.143-0.000068 \cdot V g \cdot S B+0.00000177 \cdot H^{2}-0.000854 H
\end{aligned}
$$

Table 2 Regression summary

\begin{tabular}{|c|c|c|c|c|}
\hline $\begin{array}{c}\text { Investigated } \\
\text { parameters }\end{array}$ & ratio $\boldsymbol{R}$ & $\boldsymbol{F} / \boldsymbol{F}_{\boldsymbol{k r}}$ & $\boldsymbol{p}$-value & $\begin{array}{c}\text { Standard error of } \\
\text { estimate }\end{array}$ \\
\hline Surface roughness Ra & 0.97 & 40.6 & 0.0003 & 0.07142 \\
\hline Flatness deviation $W$ & 0.89 & 5.2 & 0.005 & 0.00028 \\
\hline
\end{tabular}

A correlation matrix of the adopted independent variables and the output variable was created to observe the degree of the linear relationship between the variables (Table 3, Table 4).

\begin{tabular}{|c|c|c|c|c|c|c|c|c|c|c|}
\hline \multirow{2}{*}{$\begin{array}{c}\text { Independent } \\
\text { variable }\end{array}$} & \multicolumn{10}{|c|}{ Correlations of the flatness deviation (W) } \\
\hline & $H$ & $V g$ & $S B$ & $H^{2}$ & $V g^{2}$ & $S B^{2}$ & $H^{*} \mathrm{Vg}$ & $H^{*} S B$ & $V g^{*} S B$ & $w$ \\
\hline$H$ & 1 & 0 & 0 & 0.9983 & 0 & 0 & 0.9474 & 0.8714 & 0 & 0.2873 \\
\hline$V g$ & 0 & 1 & 0 & 0 & 0.9998 & 0 & 0.3158 & 0 & 0.5139 & -0.3189 \\
\hline$S b$ & 0 & 0 & 1 & 0 & 0 & 0.9995 & 0 & 0.4841 & 0.8566 & -0.6126 \\
\hline$H^{2}$ & 0.9983 & 0 & 0 & 1 & 0 & 0 & 0.9458 & 0.8700 & 0.0019 & 0.3134 \\
\hline$V g^{2}$ & 0 & 0.9998 & 0 & 0 & 1 & 0 & 0.3157 & 0.0011 & 0.5138 & -0.3119 \\
\hline$S B^{2}$ & 0 & 0 & 0.9995 & 0 & 0 & 1 & 0.0012 & 0.4839 & 0.8561 & -0.6085 \\
\hline$H^{*} V g$ & 0.9474 & 0.3158 & 0 & 0.9458 & 0.3157 & 0.0012 & 1 & 0.8276 & 0.1635 & 0.1859 \\
\hline$H^{*} S b$ & 0.8714 & 0 & 0.4841 & 0.8700 & 0.0011 & 0.4839 & 0.8276 & 1 & 0.4165 & -0.0104 \\
\hline$V g * S B$ & 0 & 0.5139 & 0.8566 & 0.0019 & 0.5138 & 0.8561 & 0.1635 & 0.4165 & 1 & -0.6643 \\
\hline
\end{tabular}

Table 3 A correlation matrix of the adopted independent variables and the output variable

It can be seen that there is no linear correlation between the predictors $H, V b, S B$. After checking at a later stage of the analysis of the scatter plots (Figure 2), it was found that there was also no non-linear relationship between them. Results from the adopted design of the experiment, where the explanatory variables were determined independently of each other, is a desirable feature because it indicates the uniqueness of the prediction. It can also be seen that individual effects are transformations of predictors and must have a specific relationship, hence correlation values different from zero between the other effects. It can be stated that there is a linear correlation between the flatness deviation $W$ and the $S B$ parameter $(r=-0.61)$. Analysis of the correlation matrix for the surface roughness regression equation (Table 4), as in the previous model, the independent contribution of each of the predictor variables is visible (no linear correlation between $\mathrm{H}, \mathrm{Vg}, S B$ ). There is a strong linear relationship between the dependent variable $\mathrm{Ra}$ and the independent $\mathrm{H}$, whereas there is a weak relationship between $V g$ and $R a$ (Figure 3). The highest linear correlation occurs between the 
product of the predictors $H S B$ and $R a$. It proves the complex influence of the adopted independent variables on the analyzed value of the Ra parameter.

Table 4 A correlation matrix of the adopted independent variables and the output variable

\begin{tabular}{|c|c|c|c|c|c|c|c|c|c|c|}
\hline \multirow{2}{*}{ Independent variable } & \multicolumn{10}{|c|}{ Correlations of the roughness parameter Ra } \\
\hline & $H$ & $V g$ & $S B$ & $H^{2}$ & $V g^{2}$ & $S B^{2}$ & $H^{\star} V g$ & $H^{*} S B$ & $V g^{*} S B$ & Ra \\
\hline$H$ & 1 & 0 & 0 & 0.9983 & 0 & 0 & 0.9474 & 0.8714 & 0 & 0.8733 \\
\hline$V g$ & 0 & 1 & 0 & 0 & 0.9998 & 0 & 0.3158 & 0 & 0.5139 & -0.1845 \\
\hline$S b$ & 0 & 0 & 1 & 0 & 0 & 0.9994 & 0 & 0.4841 & 0.8565 & 0.3813 \\
\hline$H^{2}$ & 0.9983 & 0 & 0 & 1 & 0 & 0 & 0.9458 & 0.8699 & 0.0019 & 0.8739 \\
\hline$V g^{2}$ & 0 & 0.9998 & 0 & 0 & 1 & 0 & 0.3157 & 0.0010 & 0.5138 & -0.182 \\
\hline$S B^{2}$ & 0 & 0 & 0.9994 & 0 & 0 & 1 & 0.0011 & 0.4838 & 0.8561 & 0.3795 \\
\hline$H^{*} V g$ & 0.9474 & 0.3158 & 0 & 0.945 & 0.3157 & 0.0011 & 1 & 0.8276 & 0.1635 & 0.7637 \\
\hline$H^{*} S b$ & 0.8714 & 0 & 0.4841 & 0.869 & 0.0010 & 0.4838 & 0.8276 & 1 & 0.4165 & 0.9468 \\
\hline$V g^{*} S B$ & 0 & 0.5139 & 0.8566 & 0.001 & 0.5138 & 0.8561 & 0.1635 & 0.4165 & 1 & 0.2296 \\
\hline
\end{tabular}

The next step is to check the scatter plots between the effects of the regression equation so as to empirically confirm or deny the existence of a linear correlation because it may happen that there is a non-linearity or the factor has been falsely evaluated based on e.g. outliers. The following are the scatter charts (Figure 2, Figure 3) for the regression equations 2 and 3 respectively.


Figure 2 Scatter plots for the flatness deviation regression matrix 



Figure 3 Scatter plots for the roughness Ra regression matrix

The above chart confirms the lack of a relation between the adopted independent variables. $S B(H), V g(H)$, $\mathrm{Vg}(\mathrm{SB})$ exclude the existence of a linear correlation between these variables. A strong linear correlation can be observed on the W (SB Vg), W (SB) and Ra (H SB) graphs.

During the WEDM process, electrical discharges occurs between electrode and workpiece across the height of the cut element. The discharges cause local melting and evaporation of small piece of material. In the end of single discharge debris are through to the gap. In investigated case of WEDM high workpiece (over 200 $\mathrm{mm}$ ) the erosion product which filling the gap change locally resistance of dielectric. To better understanding the influence of the investigated independent variables WEDM on the roughness $R a$ and the deviation of flatness W, the response surface plots were estimated. Based on the regression models (equations 2 - $\mathbf{3}$ ), the influence of the discharge voltage $\mathrm{Vg}$, pulse interval $S B$ and workpiece height $H$ on the $R a$ and the $W$ is shown in Figures 3, 4 respectively. The conducted experimental studies indicated there is a linear relationship between the surface roughness $R a$ and value of investigated variables of WEDM. The main influence of roughness $R a$ have the pulse interval $S B$ and workpiece height. The increase in the time interval causes a decrease in the linear cut speed of the wire. It leads to increasing the number of electric discharges across the path. The obtained discharge craters on the path have a larger depth causing to increase a roughness $R a$. Furthermore, increasing of high of cut workpiece leads to rising the number of debris along the gap. A local change in dielectric resistance along the gap leads to instability of discharges and an increase in surface roughness. The presented dependence also has effects on the flatness deviation. The debris may increase the number of electrical discharge in one place of the gap. Furthermore, non-uniform distribution of the electrical discharges on the tool electrode results in wire vibration. The amplitude of the vibration is "reflected" on the workpiece. Analyses of measuring reports of flatness deviations indicate that the maximum deviation value for the analyzed cases is in the near central part of the surface of the cut samples (there are concave surface areas). The shape errors are associated with the vibrations of the tool electrode. The increase of the discharge voltage VG causes the initiation of discharges at a greater distance of the electrode from the workpiece. For greater thickness of the electrode gap, the removal of debris is facilitated, increasing machining stability, which leads to reduced electrode vibration. Furthermore, increasing of time interval $S B$ significantly affects the stabilization of electrical discharges. 


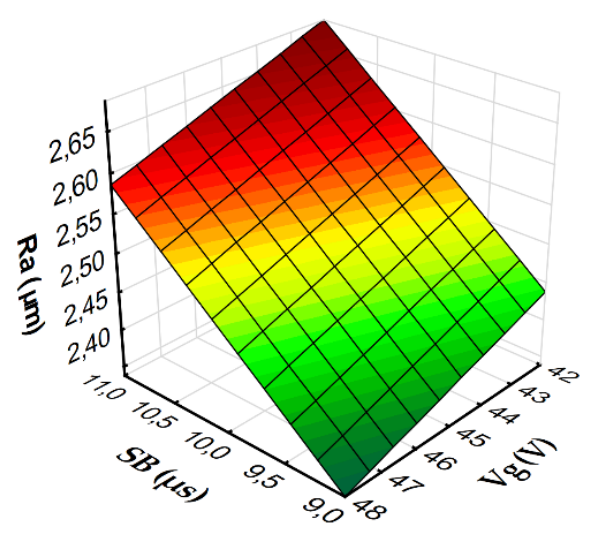

(a)

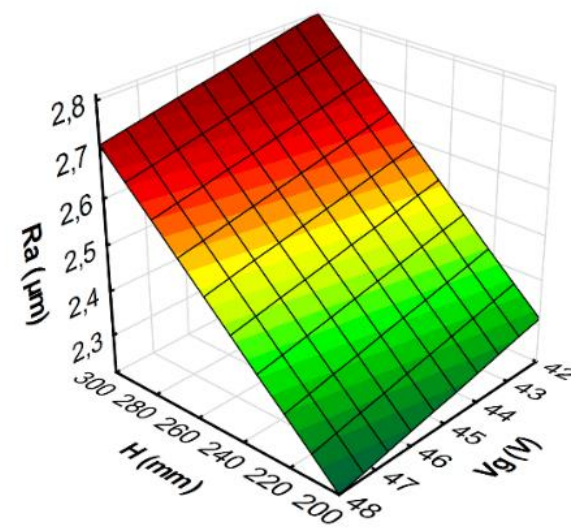

(b)

Figure 4 Estimated response surface plot for the roughness Ra: (a) constant $H=200 \mathrm{~mm}$,

(b) constant $S B=10 \mu \mathrm{s}$

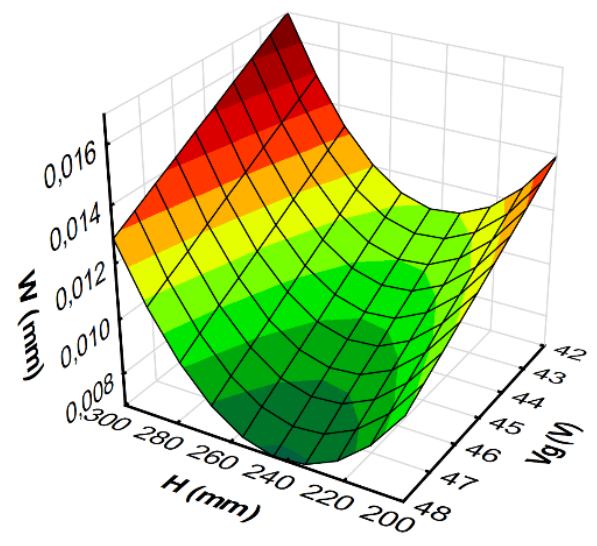

(a)

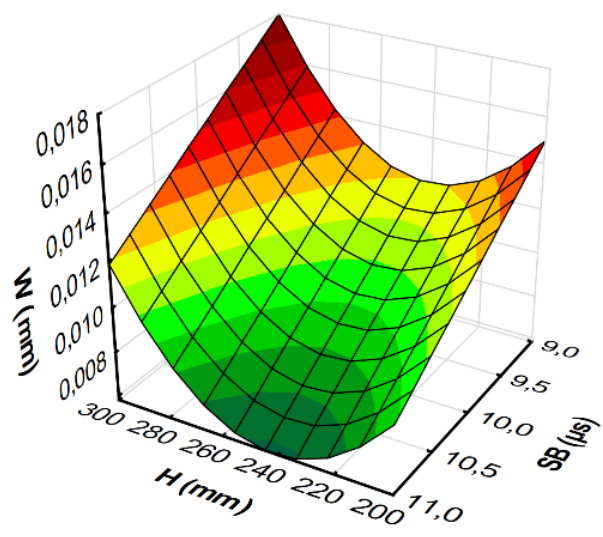

(b)

Figure 5 Estimated response surface plot for the flatness deviation W: (a) constant $S B=10 \mu \mathrm{s}$,

(b) constant $V g=42 \mathrm{~V}$

\section{CONCLUSIONS}

The experimental studies were focused on the analyses of influence WEDM parameters on the roughness $R a$ and flatness deviation during machining of tool steel X153CrMoV12. The analysis of the material removal physics indicated potential sources of shape errors of cutting parts. Based on the theoretical analyses and experimental research, the following conclusions were obtained:

- The roughness parameter $R a$ was the range of $2.08-2.68 \mu \mathrm{m}$ and corresponded to finishing and semi finishing machining. The main influence of roughness Ra have the pulse interval SB and workpiece height. The increase in the time interval causes a decrease in the linear cut speed of the wire. It leads to increasing the number of electric discharges across the path. Furthermore, increasing of high of cut workpiece leads to rising the number of debris along the gap. A local change in dielectric resistance along the gap leads to instability of discharges and an increase in surface roughness

- The developed regression equations could be used in wire electrical discharge machining of tool steel $\mathrm{X} 153 \mathrm{CrMoV} 12$ as a guideline for the selection of WEDM parameters. For appropriate selection of machining conditions it is possible to significantly reduce the shape deviation of the cut elements. 


\section{ACKNOWLEDGEMENTS}

\section{This study was conducted with financial support from the Warsaw University of Technology, hereby gratefully acknowledged.}

\section{REFERENCES}

[1] PACZKOWSKI T., ZDROJEWSKI J. The Mechanism of ECM Technology Design for Curvilinear Surfaces, Procedia CIRP, Vol. 42, 2016, pp. 356-361.

[2] DĄBROWSKI L., PACZKOWSKI T. Computer simulation of two-dimensional electrolyte flow in electrochemical machining, Elektrokhimiya, Vol. 41, Issue 1, 2005, pp. 102-110.

[3] SPADŁO S., MŁYNARCZYK P. Selected properties of the micro electrical discharge alloying process using copper electrode on aluminum, Transportation Research Procedia, 2019, 40, pp. 96-101.

[4] SPADLO, S., DEPCZYŃSKI, W., MLYNARCZYK, P. Modification of the surface layer of magnesium with 1050A aluminum alloy using electrospark deposition, IOP Conference Series: Materials Science and Engineering, 2019, $629(1), 012017$.

[5] STRAKA, L., DITTRICH, G. Influence of graphite tool electrode shape on TWR and MRR at EDM, MM Science Journal, 2019, pp. 3479-3485.

[6] GOLABCZAK, A., GOLABCZAK, M., KONSTANTYNOWICZ, A., SWIECIK, R., GALANT, M. Modeling and experimental investigations of the surface layer temperature of titanium alloys during AEDG processing, Defect and Diffusion Forum, Vol. 365, 2015, pp. 63-70.

[7] SAŁACIŃSKI T., PRZESMYCKI A., CHMIELEWSKI T. Technological aspects in manufacturing of non-circular gears, Applied Sciences, 2020, 10, 3420.

[8] HOLUBEK R., RUZAROVSKY, R. The methods for increasing of the efficiency in the intelligent assembly cell, Applied Mechanics and Materials, Vol. 470, 2014, pp. 729-732.

[9] RADZIEJEWSKA, J. Application of a nanosecond laser pulse to evaluate dynamic hardness under ultra-high strain rate. Optics \& Laser Technology, 2016, vol. 78, pp. 125-133.

[10] ŚWIERCZ, R. and ONISZCZUK-ŚWIERCZ, D. Investigation of the Influence of Reduced Graphene Oxide Flakes in the Dielectric on Surface Characteristics and Material Removal Rate in EDM. Materials 2019, $12,943$.

[11] ŚWIERCZ, R. and ONISZCZUK-ŚWIERCZ, D. The Effects of Reduced Graphene Oxide Flakes in the Dielectric on Electrical Discharge Machining. Nanomaterials 2019, 9, 335.

[12] BADIDA, M., GOMBAR, M., MASLEJOVA, A., SOBOTOVA, L. KMEC, J. and VAGASKA, A. Evaluation of zinc coating quality by statistical methods. Przemysl Chemiczny, 2015, 94, pp. 2146-2149. 